
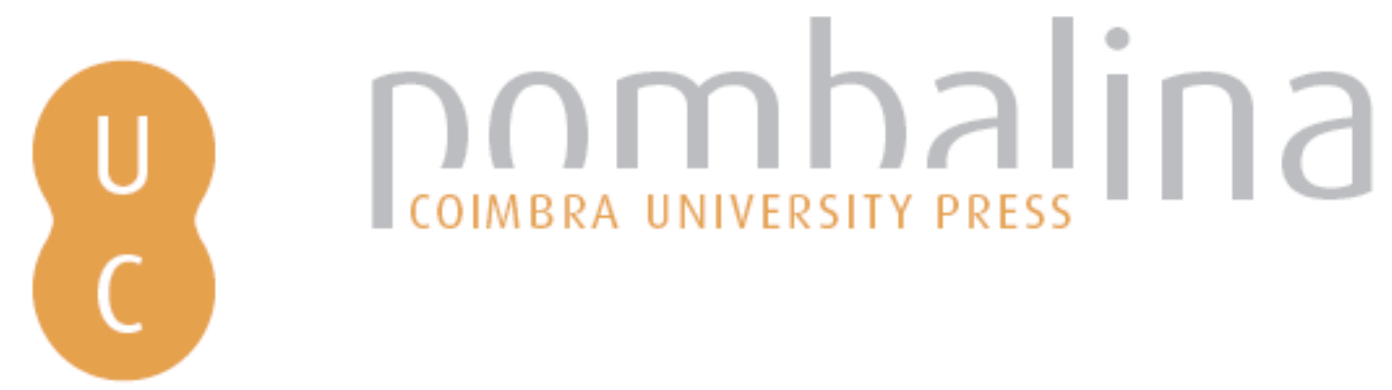

Os fluxos de escoamento sub-superficiais e sua relação com os processos
devoçoracamento: um processo dinâmico de capturação de bacias hidrográficas
Autor(es):
Pereira, Kátia Gisele de Oliveira; Pedrosa, António de Sousa
Publicado por:
Imprensa da Universidade de Coimbra; RISCOS - Associação
Portuguesa de Riscos, Prevenção e Segurança

URL persistente:

DOI: $\quad$ DOI:http://dx.doi.org/10.14195/978-989-96253-3-4_39

Accessed : $\quad$ 26-Apr-2023 05:04:05

A navegação consulta e descarregamento dos títulos inseridos nas Bibliotecas Digitais UC Digitalis, UC Pombalina e UC Impactum, pressupõem a aceitação plena e sem reservas dos Termos e Condições de Uso destas Bibliotecas Digitais, disponíveis em https://digitalis.uc.pt/pt-pt/termos.

Conforme exposto nos referidos Termos e Condições de Uso, o descarregamento de títulos de acesso restrito requer uma licença válida de autorização devendo o utilizador aceder ao(s) documento(s) a partir de um endereço de IP da instituição detentora da supramencionada licença.

Ao utilizador é apenas permitido o descarregamento para uso pessoal, pelo que o emprego do(s) título(s) descarregado(s) para outro fim, designadamente comercial, carece de autorização do respetivo autor ou editor da obra.

Na medida em que todas as obras da UC Digitalis se encontram protegidas pelo Código do Direito de Autor e Direitos Conexos e demais legislação aplicável, toda a cópia, parcial ou total, deste documento, nos casos em que é legalmente admitida, deverá conter ou fazer-se acompanhar por este aviso.

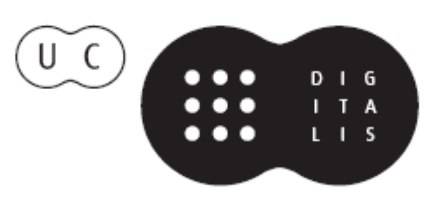



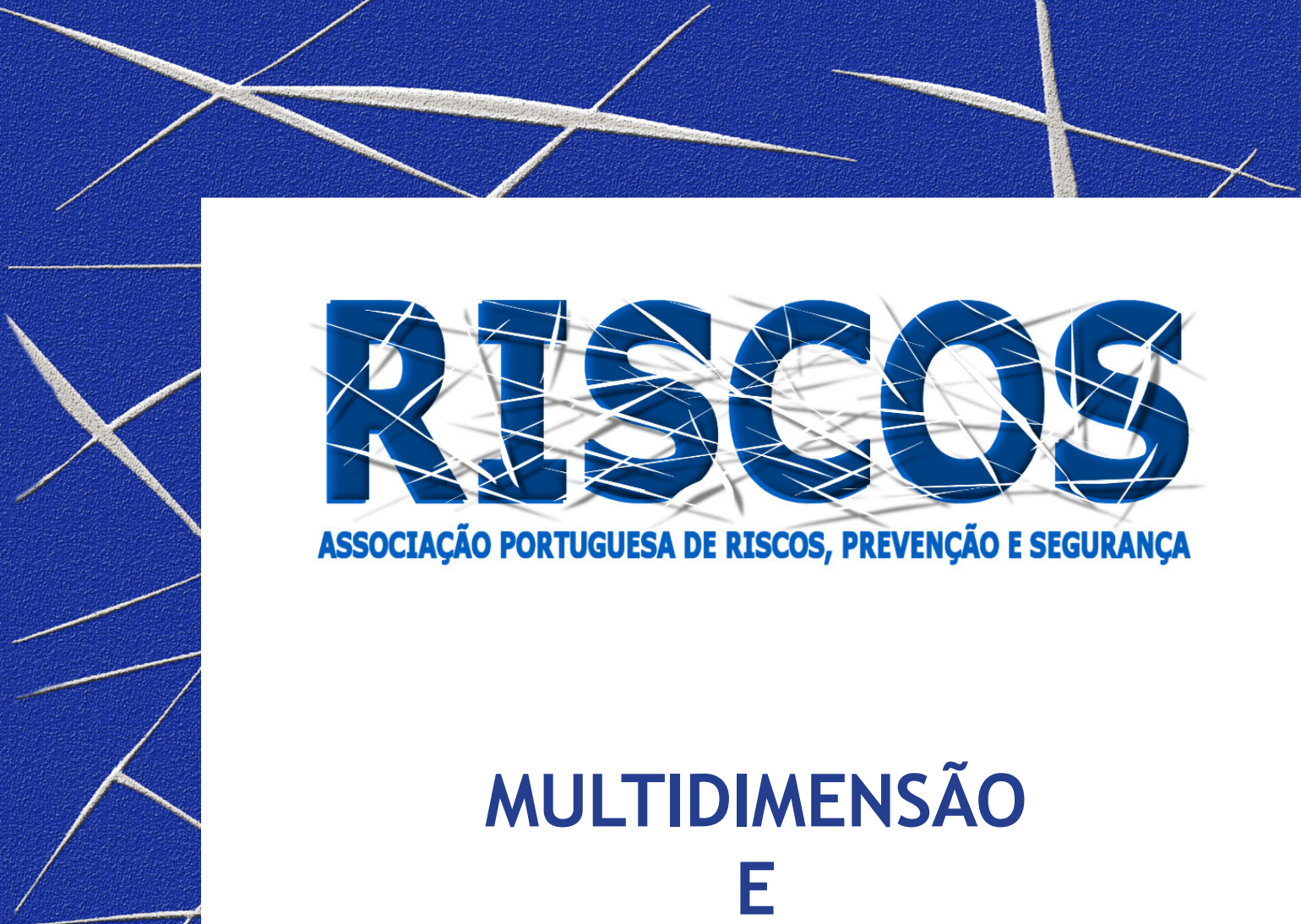

ASSOCIAÇÃO PORTUGUESA DE RISCOS, PREVENCCÃO E SEGURANÇA

MULTIDIMENSÃO

E
TERRITÓRIOS DE RISCO

III Congresso Internacional

I Simpósio Ibero-Americano

VIII Encontro Nacional de Riscos

Guimarães

2014 


\title{
OS FLUXOS DE ESCOAMENTO SUB-SUPERFICIAIS E SUA RELAÇÃO COM OS PROCESSOS DE VOÇORACAMENTO: UM PROCESSO DINÂMICO DE CAPTURAÇÃO DE BACIAS HIDROGRÁFICAS.
}

\author{
Kátia Gisele de Oliveira Pereira \\ Curso de Geografia/RISCOS \\ katia_gisele@hotmail.com \\ António de Sousa Pedrosa
}

Instituto de Geografia da UFU, CEGOT, RISCOS

aspedros@gmail.com

\section{Introdução}

Esse trabalho foi desenvolvido na área que corresponde às bacias dos ribeirões Doudinho, Panga e Estiva, afluentes do rio Tijuco, delimitadas pelas seguintes coordenadas geográficas: $19^{\circ} 00^{\prime}$ e $48^{\circ} 10^{\prime}$ de latitude sul e $19^{\circ} 20^{\prime}$ e $48^{\circ} 50^{\prime}$ de longitude oeste do meridiano de Greenwich, correspondendo a uma área de 1.301,95 $\mathrm{km}^{2}$. Essa área corresponde ao contato da chapada com o relevo dissecado da bacia do rio Tijuco (MG). A origem paleogeográfica da área de pesquisa conta com a evidência tanto de soerguimentos, como de movimentação de subsidência de blocos. Segundo Batezelli (2003) tais processos são consequências dos esforços impostos às placas sul-americanas durante a separação Brasil-África. Figura 1.

As subsidências descritas ocorreu em função da instalação de intrusões alcalinas que deram origem aos plugs vulcânicos de Tapira, em Araxá-MG, Salitre, Serra Negra e Catalão, o chamado Soerguimento Alto Paranaíba (SAP). Ao mesmo tempo, as tais subsidências deram origem a uma nova depressão, alongada segundo a direção aproximada de Nordeste - Sudoeste, que se estendiam do Sul de Goiás até o Sudoeste do Estado de São Paulo, denominando esse embaciamento como Bacia Bauru. Essa abordagem tectono-sedimentar para evolução da Bacia Bauru já se encontra bastante difundida na literatura geológica presente nos trabalhos de Hasui et al (1975), Riccomini (1997), Milani et al (2007), Pereira et al (2012). Figura 2.

O desenvolvimento das formas do relevo foram submetidas as combinações de atividades da tectônicas, das características litológicas, das práticas antrópicas e da dinâmica do clima, obedecendo ao arranjo as escalas que compreendem a bacia do Paraná, até as formas locais como o caso do contato da chapada com o relevo dissecado da bacia do rio Tijuco (MG). 


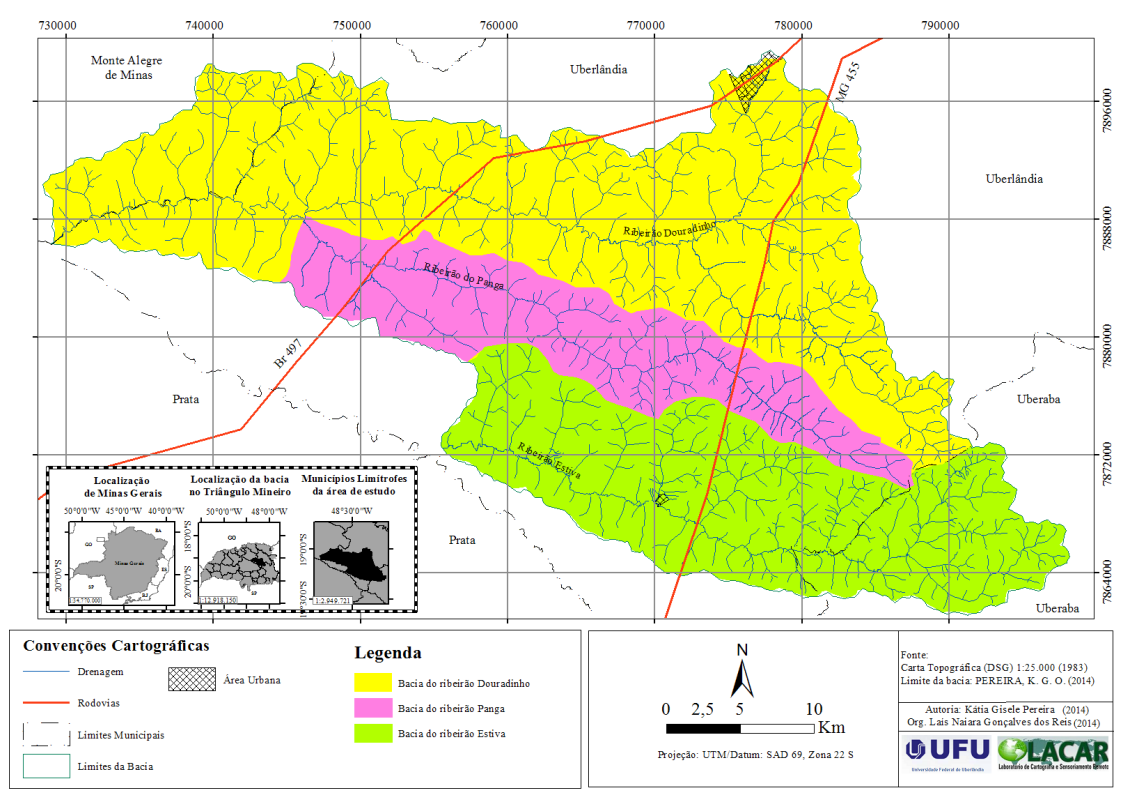

Figura 1 - Localização da Área de Estudo.

Fonte: Cartas topográficas do Exército, (DSG, 1983), escala 1:25.000

A análise do comportamento das formas do relevo, dos padrões e da dinâmica das drenagens superficiais e subsuperficiais, podem ser compreendida por esse aspecto como aponta Facincani (2000).
As descontinuidades estruturais associadas aos regimes tectônicos têm relevante função na origem e evolução das formas de relevo, visto que determinam as vias de percolação da água e aceleram os processos intempéricos (morfogênese e pedogênese). (FACINCANI, (2000 p.11)

A origem das voçorocas que ocorrem no município de Uberlândia foi atribuída aos elevados índices de erodibilidade dos solos; a intensidade das primeiras chuvas de verão - por seu caráter torrencial - seguidas de um período de estiagem, típicos do planalto central brasileiro e ao desmatamento, Baccaro (1990) e Guerra e Botelho (1998). Assim, o estudo da geomorfologia estrutural, presente nesse artigo, remete-se, com ênfase, ao estudo da origem e evolução das formas do relevo relativas derivadas direta e indiretamente dos movimentos tectônicos verticais e horizontais, Facincani (2000). Espera-se apontar de que forma a atuação da tectônica tem contribuído para a dinâmica de capturas de cabeceiras de drenagem, para a ocorrência de erosão acelerada associadas as voçorocas, no intuito de explicar a dinâmica de evolução de algumas formas de relevo e das redes de drenagem subsuperficiais. 


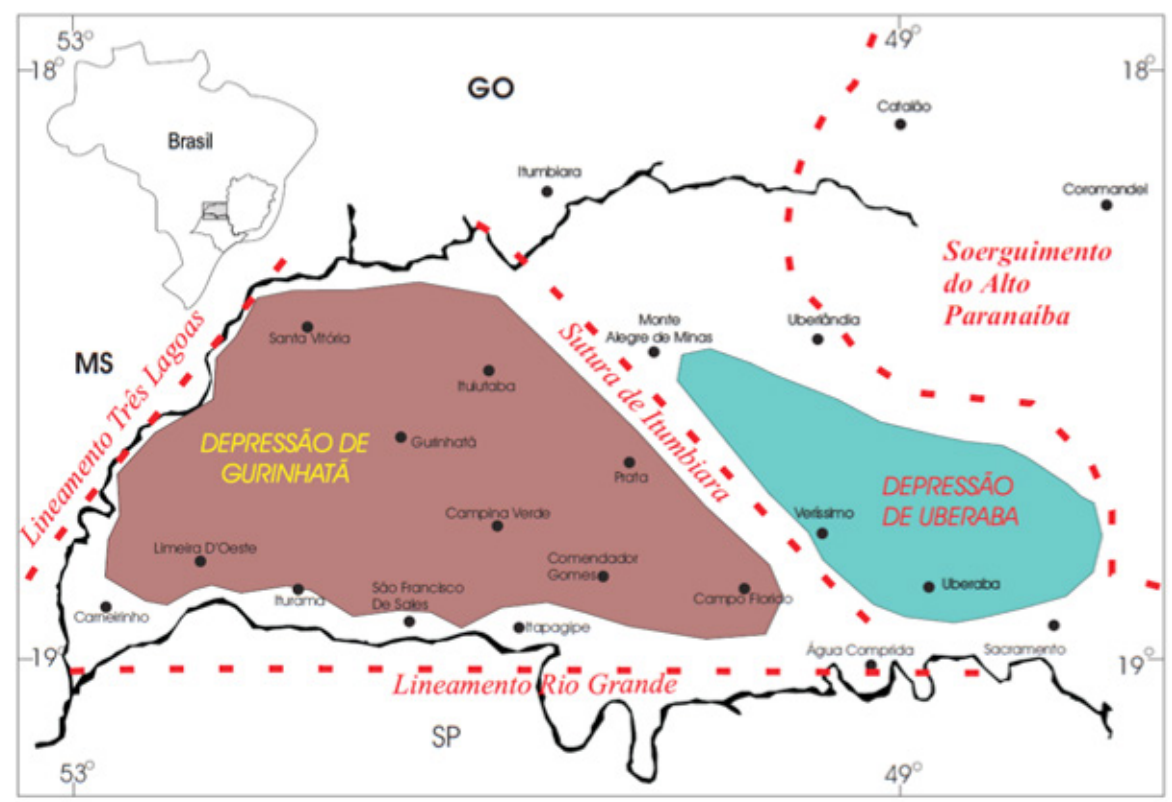

Figura 2 - Compartimentação Estrutural do Triângulo Mineiro (MG).

Fonte: Batezelli (2003).

As evidências morfotectônicas no contato da chapada com o relevo dissecado da Bacia do rio Tijuco (MG).

De acordo com Batezelli (2003), desde o Permiano Superior a Bacia do Paraná deixou de ser uma unidade autônoma de sedimentação, de forma que a deposição Juro-Triássica excedeu os limites da Bacia Paraná, estendendo-se para as áreas vizinhas sobre rochas pré-cambrianas e paleozoicas. Dessa forma, a Flexura Goiânia teria sido palco de movimentação de falhas, fruto de tectônica tangencial durante a reativação tectonomagmática Wealdeniana. Sobre essa estrutura então foram depositadas rochas dos Grupos São Bento, os basaltos e os arenitos do Grupo Bauru, condicionadas por falhas com orientação NW - NNW.

A porção norte e nordeste da bacia do Paraná, na qual está inserida a área de pesquisa tornouse ambiente de deposição, no período neocretácico, preenchido por sequência arenosa siliciclástica em clima semiárido, com sedimentos provenientes de alterações e erosão de rochas paleozóicas e pré-cambrianas de área fonte das bordas da bacia. O Grupo Bauru é representado nesta área por: i) arenitos da Formação Marília que foi gerada em sistemas de leques aluviais marginais; ii) a Formação Adamantina que está relacionada com sistemas fluviais de rios anastomosados e planícies com lagoas efêmeras nas porções centro e nordeste da bacia; iii) a Formação Uberaba, restrita ao extremo nordeste da bacia do Paraná, com contribuição de material vulcânico piroclástico.

O embasamento litológico compõe-se de rochas basálticas oriundas do intenso vulcanismo fissural de ocorrência no Mesozóico. Segundo Nishiyama (1989), o basalto aflora no vale dos principais rios e ribeirões em que suas camadas são expostas pela ação erosiva da água. Os 
arenitos da Formação Adamantina são arenitos marrom-avermelhados apresentando cimentação carbonática e intercalados por arenitos argilosos e leques de argilitos. Os arenitos da Formação Uberaba são reconhecidos pela contribuição vulcanoclástica de coloração esverdeada e acinzentada. Segundo Batezelli (2003), Almeida e Barbosa (1953), Fernandes (2004) a designação Formação Marília foi empregada para os sedimentos clásticos grossos da parte superior do Grupo Bauru, caracterizados por presença de nódulos e de cimentação carbonática.

Os arenitos da Formação Marília são divididos em Membro Serra da Galga contendo arenitos imaturos, com fácies conglomeráticas de cimentação carbonática (CaCO3). variada e conglomerados. O Membro Ponte Alta contendo lentes de calcário silicoso e conglomerado basal e os conglomerados carbonáticos. A área foi classificada por Baccaro (1991), como sendo de relevo medianamente dissecado em que os topos são nivelados entre 620 e 930 metros, englobando vertentes convexas e suaves, com declives compreendidos entre os $3^{\circ}$ nos topos e $15^{\circ}$, no entalhamentodas cabeceiras de drenagem. Isso implica em dizer que exceto no sobressalto que há entre alguns pontos da chapada com o disecado, a área como um todo é ralativamente plana e pouco dissecada.

No topo da chapada os vales são do tipo vereda, representado por vales rasos (baixa dissecação) e na área do relevo dissecado o grau de entalhamento é bastante expressivo. 0 contato dessa área apresenta características de movimentação tectônica, podendo ser a causa do intenso voçorocamento nela instalado. A suavidade do contato da chapada é rompida por fortes e abruptas declividades. Ora ocorre o avanço da voçoroca, como apresenta na figura 3, ora esse avanço se encontra um rebordo erosivo sustentado por arenitos da Formação Marília, com forte cimentação carbonática. Figura 4. 0 afloramento do nível freático nas áreas de contato podem demonstrar como ocorre a captura da drenagem demonstrado pela ocorrência de extensas e profundas voçorocas, que variam de 300 - 400 de extensão, em que o desnível varia de 30 a 50 metros.

Os aspectos mais expressivos de voçorocamento pode ser relacionado a atividade da tectônica, pois foram encontrados preferencialmente, nas bordas Norte e Leste da área. Essa área tem uma forte presença de falhas no sentido N-S, E-W ao norte, N-S e NW-SE, a Leste. As voçorocas encontradas possuem esse alinhamento, o que evidencia a presença de levantamento da chapada e subsidência da área dissecada. 


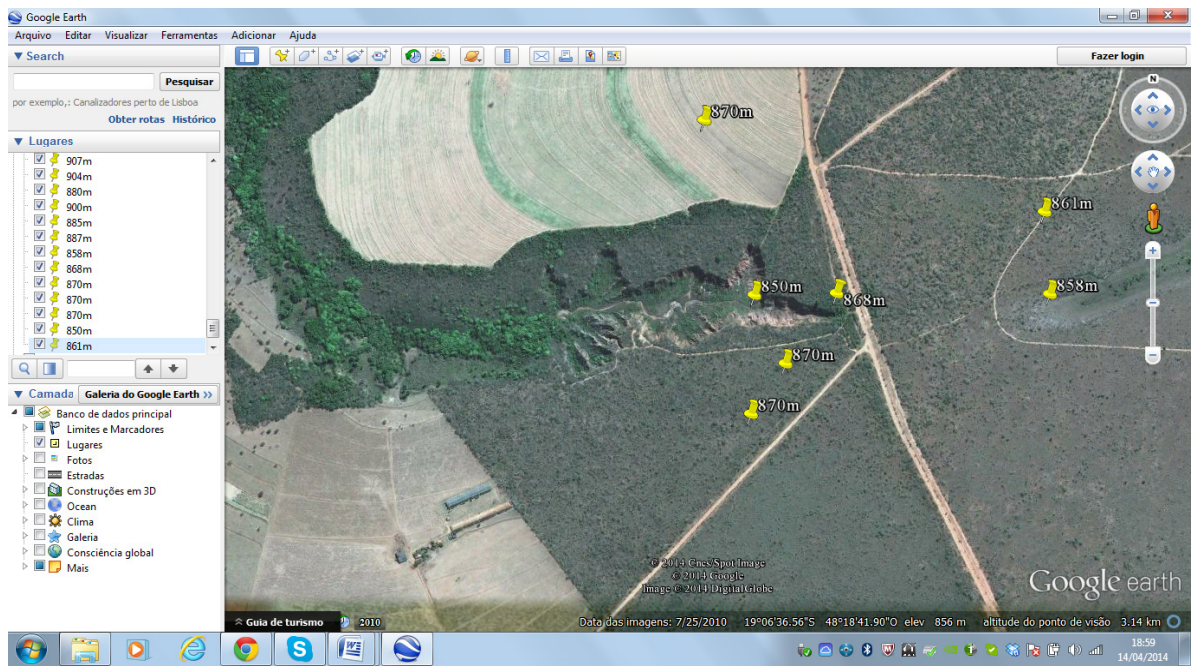

Figura 3 - Voçoroca do Tatu no Contato com a Chapada.

Fonte: Pereira e Pedrosa (2014).

Nota: localização de $19^{\circ} 06^{\prime} 21^{\prime \prime}$ 'S e $48^{\circ} 18^{\prime} 33^{\prime \prime}$ W.

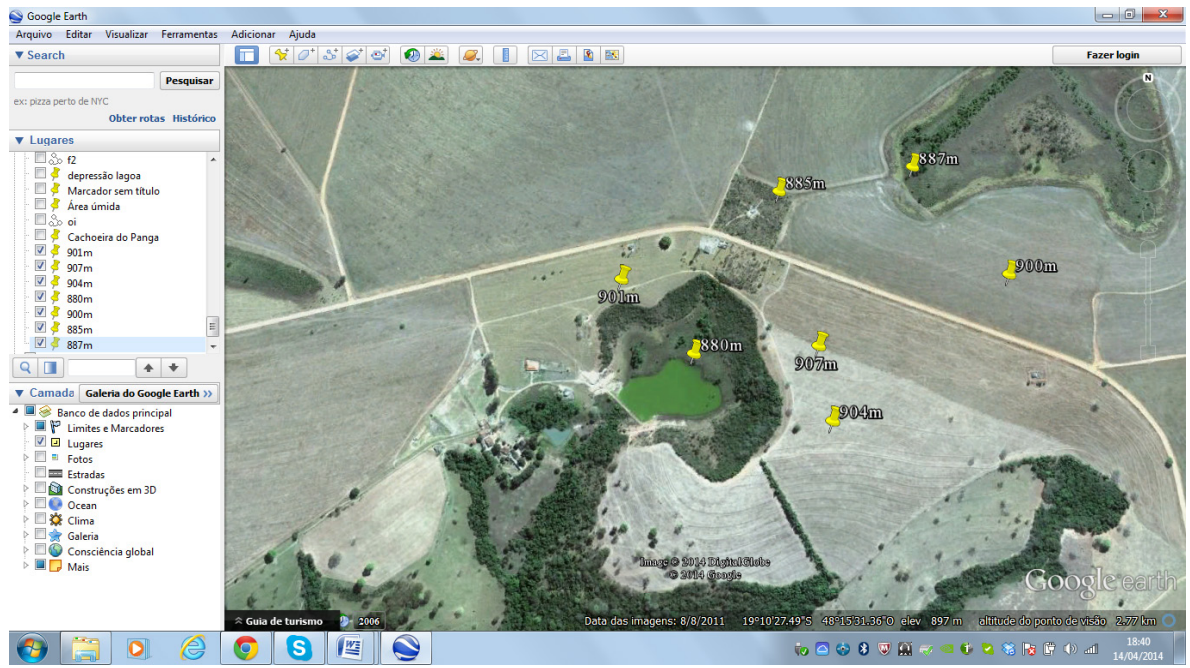

Figura 4 - Contato da chapada com o relevo dissecado e a direção dos fluxos superficiais (vereda) e subsuperficiais (rebordo erosivo) . Fonte: Pereira e pedrosa (2014).

Nota: localização: $19^{\circ} 10^{\prime} 38.86^{\prime \prime}$ ', $48^{\circ} 15^{\prime} 8.39^{\prime \prime} \mathrm{W}$ 


\section{Considerações Finais}

Nas cabeceiras dos principais cursos de água ocorrem a captura de drenagem por recuo das cabeceiras, com captura do fluxo sub-superficial. Neste compartimento são encontrados intensos voçorocamentos alinhados com as rupturas nas vertentes e também, com o rebaixamento do nível de base. Os fatores que estão na base da gênese deste processo são diversos: i) forte concentração da precipitação no período chuvoso (outubro-março) desta região: ii) ocupação humana pouco ordenada associada ao forte desmatamento que se verificou pós década de setenta do século passado; iii) a alta susceptibilidade dos solos; iv) a importância dos fluxos sub-superficiais; v) a tectônica ativa pode ter levado a rearranjos morfológicos e, consequentemente a alterações nos fluxos de drenagem sub-superficiais, com consequências na dinâmica dos voçorocamentos. Este último aspecto pode ter levado que a forte dinâmica subsuperficial associada às voçorocas tenha contribuido para a ocorrencia de capturas recentes no sistema de rede de drenagem.

\section{Agradecimentos}

Agradecemos o apoio dado a esse trabalho pela FAPEMIG - Fundação de Amparo à Pesquisa de Minas Gerais.

\section{Bibliografia}

ALMEIDA, F. F. M.; BARBOSA, O. (1953) - Geologia das quadrículas de Piracicaba e Rio Claro, Estado de São Paulo. Rio de Janeiro, DNPM/DGM.

BACCARO, C. A. D. As Unidades Geomorfológicas e a Erosão nos Chapadões do Município de Uberlândia. Sociedade \& Natureza, n. 11 e 12, p. 19-34, 1994.

BACCARO, C. A. D. (1990) - Estudos dos Processos Geomorfológicos de Escoamento Pluvial em Área de Cerrado. Uberlândia - MG. 1990. (Tese de Doutorado). Instituto de Geografia (IG), Departamento de Geografia (DEGEO), Faculdade de Filosofia, Letras e Ciências Humanas (FFLCH), USP, São Paulo.

BATEZELLI, A. (2003) - Análise da sedimentação cretácea no Triângulo Mineiro e sua correlação com áreas adjacentes. Instituto de Geociências e Ciências Exatas. Rio Claro, Universidade Estadual Paulista UNESP. Doutorado em Geociências.

FACINCANI, E. M. (2000) - Morfotectônica da Depressão Periférica Paulista e Cuesta Basáltica: regiões de São Carlos, Rio Claro e Piracicaba, SP. 249 p. (Tese de Doutorado). Rio Claro, Instituto de Geociências, Universidde Estadual Paulista - UNESP.

FERNANDES, L. A. (2004) - Mapa Litoestratigráfico da Parte Oriental da Bacia Bauru (PR, SP, MG), Escala 1:1.000.000 Boletim Paranaense de Geociências, v. 55, p. 53-66.

GUERRA, A. J. T.; BOTELHO, R. G. M. (1998) - Erosão dos Solos. In: CUNHA, S. B. E. G., A. J. T. (Ed.). Geomorfologia do Brasil. Rio de Janeiro, Bertrand Brasil. p.181 - 227.

HASUI, Y. et al. (1995) - The Phanerozóic Tectonic Evolotion of the Minas Gerais. Anais da Academia Brasileira de Ciência, v. 47, n. 314, p. 431-438.

MILANI, E. J. et al. (2007) - Bacia do Paraná. Boletim de Geociências Petrobras, v. 15, n. 2, p. 265-287.

PEREIRA, E. et al. (2012) - A Evolução das Sinéclesis Paleozóicas: Província Solimões, Amazonas, Parnaíba e Paraná. In: HASUI, Y.;CARNEIRO, C. D. R., et al (Ed.). Geologia do Brasil. São Paulo, Becca. p.374394.

RICCOMINI, C. (1997) - Arcabouço Estrutural e Aspectos do Tectonismo Gerador e Deformador da Bacia Bauru no Estado de São Paulo. Revista Brasileira de Geociências v. 27, n. 2, p. 153-162. 